\title{
COMPUTER CONFERENCE STUDENT PAPER COMPETITION
}

The National Conference on the Use of On-Line Computers in Psychology will continue to sponsor an award for the outstanding student paper submitted for presentation at the annual meetings. Papers may be submitted across a broad range of computer-related topics, including, but not limited to: (1) innovative programming for on-line research, for simulation models, or for statistical procedures; (2) innovative hardware design for computer configurations, for peripheral devices, or for interface and communication networks; (3) applications of computers to psychology in new experimental paradigms, stimulus generation, or response collection procedures. Papers may be theoretical, experimental, and/or applied in approach. Eligibility is limited to (1) work done by a student currently enrolled in courses or (2) work done as a part of course, thesis, or other student research by a person who graduated within the year preceding the 1981 conference. The author of the winning paper will be invited to address the 1981 conference and will receive a complimentary 1-year membership in the conference, a complimentary 1-year subscription to Behavior Research Methods \& Instrumentation, and a $\$ 50$ cash prize.

\section{DEADLINE: AUGUST 1, 1981}

Authors must submit six copies of the full paper. A cover sheet should include the author's name, mailing address, telephone number, and academic affiliation, a 50-word abstract, and a selfaddressed stamped postcard and envelope. Send these materials to John Cotton, Department of Education, University of California, Santa Barbara, California 93106, or Cynthia Null, Department of Psychology, College of William and Mary, Williamsburg, Virginia 23185. 